\title{
Factors and Prognostic Significance of Impaired Exercise Tolerance in Women over 40 with Arterial Hypertension
}

\author{
Agata Bielecka-Dabrowa ${ }^{1,2, *}$, Katarzyna Gryglewska ${ }^{3, *}$, Agata Sakowicz $^{4}{ }^{\mathbb{D}}$, Stephan von Haehling ${ }^{5}$, \\ Kamil Janikowski ${ }^{1,2}$, Marek Maciejewski ${ }^{3}$ and Maciej Banach ${ }^{1,2}$ (D)
}

1 Heart Failure Unit, Department of Cardiology and Congenital Diseases of Adults, Polish Mother's Memorial Hospital Research Institute (PMMHRI), 93-338 Lodz, Poland; kkjanikowski@gmail.com (K.J.); maciejbanach77@gmail.com (M.B.)

2 Department of Preventive Cardiology and Lipidology, Chair of Nephrology and Hypertension, Medical University of Lodz, 93-338 Lodz, Poland

3 Department of Cardiology and Congenital Diseases of Adults, Polish Mother's Memorial Hospital Research Institute (PMMHRI), 93-338 Lodz, Poland; marek.maciejewski@iczmp.edu.pl

4 Department of Medical Biotechnology, Medical University of Lodz, 93-338 Lodz, Poland; agata.sakowicz@gmail.com

5 Department of Cardiology and Pneumology and German Center for Cardiovascular Research (DZHK), Partner Site Göttingen, University Medical Center Göttingen (UMG), 37075 Göttingen, Germany; stephan.von.haehling@med.uni-goettingen.de

* Correspondence: agatbiel7@poczta.onet.pl (A.B.-D.); gryglewskak@gmail.com (K.G.); Tel.: +48-42-271-15-97 (A.B.-D. \& K.G.)

\section{check for} updates

Citation: Bielecka-Dabrowa, A.; Gryglewska, K.; Sakowicz, A.; von Haehling, S.; Janikowski, K.; Maciejewski, M.; Banach, M. Factors and Prognostic Significance of Impaired Exercise Tolerance in Women over 40 with Arterial Hypertension. J. Pers. Med. 2021, 11, 759. https://doi.org/10.3390/ jpm11080759

Academic Editor: Carlo Palombo

Received: 1 July 2021

Accepted: 28 July 2021

Published: 30 July 2021

Publisher's Note: MDPI stays neutral with regard to jurisdictional claims in published maps and institutional affiliations.

Copyright: (c) 2021 by the authors. Licensee MDPI, Basel, Switzerland. This article is an open access article distributed under the terms and conditions of the Creative Commons Attribution (CC BY) license (https:/ / creativecommons.org/licenses/by/ $4.0 /)$.

\begin{abstract}
The aim of this study was to identify factors influencing maximal oxygen uptake $\left(\mathrm{VO}_{2 \max }\right)$ and early identification of the profile of hypertensive women in the perimenopausal period at risk of heart failure. This study included 185 female patients. Regression analyses determined predictors of the lowest $\mathrm{VO}_{2 \max }$ (quartile 1: $\mathrm{VO}_{2 \max }<17 \mathrm{~mL} / \mathrm{kg} / \mathrm{min}$ ). Females with the lowest oxygen consumption had a significantly higher level of high sensitive cardiac Troponin $\mathrm{T}$ (hs-cTnT) $(p=0.001)$, higher values of the left atrial (LA) volume, late diastolic mitral annulus velocity $\left(\mathrm{A}^{\prime}\right)$, $\mathrm{E} / \mathrm{E}^{\prime}(p=0.0003, p=0.02, p=0.04$; respectively), higher BMI and fat content $(\mathrm{kg}$ and $\%)(p<0.0001)$, higher fat free mass (FFM) $(\mathrm{kg})(p<0.0001)$, total body water content (TBW) $(p=0.0002)$ as well as extracellular body water content (ECW) $(p<0.0001)$ and intracellular body water content (ICW) $(p=0.005), \mathrm{ECW} / \mathrm{TBW} \times 100 \%(p<0.0001)$ and metabolic age $(p<0.0001)$ and lower $\mathrm{E}^{\prime}(p=0.001)$ compared to controls. In a multiple logistic regression model independently associated with $\mathrm{VO}_{2 \max }$ were: $\mathrm{ECW} / \mathrm{TBW} \times 100 \%$ (OR 4.45, 95\% CI: 1.77-11.21; $p=0.002)$, BMI (OR 7.11, 95\% CI: 2.01-25.11; $p=0.002$ ) and hs-cTnT level (OR 2.69, 95\% CI: 1.23-5.91; $p=0.013$ ). High-sensitivity cardiac troponin may serve as an early biomarker of heart failure in hypertensive women. Hydration status should be considered in overall hypertensive women care. There is an importance of body mass compartments analysis in the early identification of hypertensive females at risk of heart failure. Optimization and personalization of body structure may be a preventive method for this disease. ClinicalTrials.gov Identifier: NCT04802369.
\end{abstract}

Keywords: hypertension; exercise intolerance; troponin; body mass compartments; personalization of body structure

\section{Introduction}

Arterial hypertension is the most relevant factor of cardiovascular risk affecting circulatory diseases' morbidity and mortality. It is estimated that 1.13 billion people in the world are diagnosed with hypertension [1,2]. An increasingly relevant problem in Europe, related to health and the economy, is heart failure (HF) [3]. The proportion of women is constantly growing in this group. Various studies have shown that progenitive factors, such as age at menopause, parity and polycystic ovarian syndrome (PCOS), may play a 
role in the development of HF [4,5]. Whether higher cardiovascular risk is a function of aging or a consequence of the menopause and its associated loss of endogenous estrogen has been debated in the literature for many years [6]. The loss of ovarian hormones around menopause has many adverse effects on coronary heart disease (CHD) risk factors. Hypertension is the most significant risk factor that affects women in the postmenopausal years. The onset of hypertension can cause a diversity of symptoms that are frequently attributed to menopause. Hypertension is also one of the most common conditions that can lead to HF. The Framingham study showed that hypertension was associated with 39\% of HF cases in men and 59\% in women. In both HF with reduced ejection fraction (HFrEF) and $\mathrm{HF}$ with preserved ejection fraction (HFpEF), women report a much lower quality of life as compared to men [7]. Many women over 40 years of age additionally to primary hypertension development report worsening exercise intolerance as the first symptom of HF. One of the most valuable tools to determine assessment of the functional capacity during exercise is cardiopulmonary exercise testing (CPET). The CPET provides diagnostic and prognostic data derived from the direct measurement of $\mathrm{VO}_{2}$ [8]. Therefore, we sought to determine clinical predictors of $\mathrm{VO}_{2 \max }$ decrease in middle-aged hypertensive women.

\section{Materials and Methods}

\subsection{Basic Characteristics}

In this study, 185 female patients with primary hypertension were enrolled. All subjects were hospitalized in the Department of Hypertension and Department of Cardiology and Congenital Heart Diseases of Adults between 2018 and 2020. A random sample in the electronic medical record was reviewed independently and in duplicate by two investigators (A.B.D. and K.G.) to validate the research strategy. All participants were consulted by a gynecologist at the Polish Mother's Memorial Hospital Research Institute after 12 months from final menstrual period and were classified as patients during menopausal transition. All patients included in this analysis performed symptom-limited cardiopulmonary exercise testing (CPET) within one week. Physical activity level of accessed women was low. Their lifestyle was sedentary. Maximal oxygen uptake $\left(\mathrm{VO}_{2 \max }\right)$ was reported as absolute maximal $\mathrm{VO}_{2}$, indexed to body weight and analyzed as quartiles, with quartile 1 representing the lowest $\mathrm{VO}_{2 \max }$. The patients were divided into a group that demonstrated maximal oxygen consumption measured during incremental exercise indexed per kilogram $-\mathrm{VO}_{2 \max }<17 \mathrm{~mL} / \mathrm{kg} / \mathrm{min}$ (the lowest percentile) (54 women at the age $51( \pm 8)$ years old, median $\left.\mathrm{VO}_{2 \max } 15 \mathrm{~mL} / \mathrm{kg} / \mathrm{min}\right)$ and a second group of women aged $55( \pm 8)$ years who presented $\mathrm{VO}_{2 \max }>17 \mathrm{~mL} / \mathrm{min} / \mathrm{kg}$ (131 women, median $21 \mathrm{~mL} / \mathrm{kg} / \mathrm{min}$ ). The study is in compliance with the Declaration of Helsinki and was approved by the Polish Mother's Memorial Hospital Research Institute (PMMHRI-BCO.71/2020).

Exclusion criteria:

(a) uncontrolled hypertension;

(b) diagnosis of heart failure or typical symptomatic heart failure;

left ventricular ejection fraction (LVEF) $<50 \%$;

(c) documented: hyperandrogenism, hyperestrogenism, insulin resistance, premature ovarian failure, polycystic ovary syndrome;

(d) past myocardial infarction;

(e) diagnosis of cardiomyopathy (hypertrophic, dilated, restrictive, peripartum, arrhythmogenic);

(f) lysosomal storage disorders;

(g) stroke, transient ischemic attack, intracerebral hemorrhage in medical history;

(h) severe hyper- and hypothyroidism;

(i) pregnancy and lactation;

(j) chronic kidney disease (stage IV and V according to the National Kidney Foundation) and dialysis treatment;

(k) documented neoplastic process; 
(l) the patient's inability to cooperate and/or provide informed consent to participate in the research;

(m) alcohol and drug abuse;

(n) active autoimmune disease;

(o) treatment using immunosuppressants, cytostatic drugs, glucocorticosteroids, or antiretroviral drugs;

(p) a history of bone marrow transplant or other organ transplant, treatment with blood products within the last 6 months;

(q) active systemic infection;

(r) Hepatitis $B$ virus (HBV), hepatitis $\mathrm{C}$ virus (HCV) or human immunodeficiency virus (HIV) carrier or positive for hepatitis B surface antigen (HBsAg) or antibodies to HCV;

(s) surgery or serious injury within the last month;

(t) patients who did not express their informed consent to participate in the study.

\subsection{Echocardiography}

The patients underwent echocardiography using the Vivid E95 system (GE Healthcare, Chicago, IL, USA). Numerical measures were conducted according to current guidelines [9]. Left ventricular (LV) volume and ejection fraction (EF) were derived according to the modified biplane Simpson's rule. Left atrial (LA) volume was obtained using the modified biplane Simpson's method and indexed to body surface area (LA volume index-LAVi) [10]. Residual echocardiographic parameters analyzed were the ratio of early transmitral peak velocity to early diastolic peak annular velocity $\left(E / E^{\prime}\right)$. Early diastolic $\left(E^{\prime}\right)$ and late diastolic $\left(\mathrm{A}^{\prime}\right)$ mitral annular myocardial velocity of the left ventricle were recorded using pulsedwave Doppler from the apical 4-chamber view [11]. The right ventricular (RV) measure was tricuspid annular plane systolic excursion (TAPSE).

\subsection{Laboratory Tests}

Diagnostic blood samples were collected from each patient. The samples were obtained by needle puncture and withdrawn by suction through the needle into a vacuum blood collection system. Laboratory tests were performed in the hospital laboratory. We measured liver function (alanine aminotransferase (ALT) and aspartate transaminase (ASP)); renal function (creatinine, glomerular filtration rate (GFR) estimate by Modification of Diet in Renal Disease (MDRD)) parameters, inflammatory cytokine (high-sensitivity C-reactive protein (CRP)), glucose level, lipoprotein profile: low-density lipoprotein (LDL), high-density lipoprotein (HDL) and triglycerides (TG). Additionally, the amount of hemoglobin was measured, and the analysis of $\mathrm{N}$-terminal pro B-type natriuretic peptide (NT-proBNP) and high-sensitivity cardiac troponin T (hs-cTnT) was conducted. Only high-sensitivity troponin values were used for further analysis. Biochemical tests were performed using a biochemical analyzer (AU 640 Olympus, Tokyo, Japan). The determination of high-sensitivity CRP was performed in plasma using a certified latex particle-enhanced immunologic turbidimetric assay. Plasma-glucose concentration was obtained using the hexokinase method (Olympus OSR61221, OSR6221 Tokyo, Japan). Creatinine concentrations in plasma samples were measured with a rate-blanked and compensated picric acid colorimetric assay (Olympus OSR6178, Tokyo, Japan). A spectrophotometric method for quantitative determination of hemoglobin was used. Plasma and serum were separated by centrifugation and serum hs-cTnT and NT-proBNP were measured in plasma using enzyme-linked immunosorbent assay (ELISA) tests (Roche Diagnostics, Warsaw, Poland).

\subsection{Spiroergometry}

Symptom-limited cardiopulmonary exercise testing (CPET) was performed on an electromagnetically braked upright cycle ergometer Bike M (CORTEX Biophysik GmbH, Leipzig, Germany) with a metabolic gas analyzer METALYZER 3B (CORTEX Biophysik $\mathrm{GmbH}$, Leipzig, Germany) using the MetaSoft Studio application software (CORTEX Biophysik GmbH, Leipzig, Germany) [12]. Exercise testing on a bicycle ergometer was 
preceded by spirometry. Forced vital capacity (FVC) and forced expiratory volume in one second (FEV1) were estimated. We also recorded FEV1/FVC ratio (Tiffeneau index). CPET on a bicycle ergometer was conducted with additional continuous 12-lead electrocardiogram (ECG), heart rate (HR), peripheral oxygen saturation $\left(\mathrm{SpO}_{2}\right)$ and non-invasive blood pressure (NIBP) monitoring. Exercise test had three stages: a 1 min rest phase where the patient sat on the ergometer; cycling at a constant cadence, despite changing resistance and a further 5 min of recorded rest. Initially the workload was 20 watts (W) and increased by $25 \mathrm{~W}$ every $3 \mathrm{~min}$. One of the most important measurements is $\mathrm{VO}_{2 \text { max }}$ (the maximal rate of muscle oxidative metabolism). If a plateau is not obtained during CPET, the highest $\mathrm{VO}_{2}$ attained is the $\mathrm{VO}_{2}$ peak and can be used as a substitute for $\mathrm{VO}_{2 \max }$ [13]. We also assessed other valuable CPET parameters. These derived measurements included ventilatory exchange (VE), oxygen uptake $\left(\mathrm{VO}_{2}\right), \mathrm{CO}_{2}$ expenditure $\left(\mathrm{VCO}_{2}\right)$, respiratory exchange ratio (RER), anaerobic threshold (AT), oxygen uptake at anaerobic threshold $\left(\mathrm{VO}_{2} \mathrm{AT}\right)$, and the minute ventilation/carbon dioxide production slope ( $\mathrm{VE} / \mathrm{VCO}_{2}$ slope).

\subsection{SphygmoCor}

The SphygmoCor 9.0 tonometer (AtCor Medical, Sydney, Australia) is a tool for noninvasive assessment for central arterial pressure waveform analysis [14]. We obtained the aortic systolic pressure (SP aortic), aortic diastolic pressure (DP aortic) and aortic pulse pressure (PP aortic) by using this method. Additionally, the parameters of arterial stiffness were measured: augmentation pressure (AP), augmentation index (AIx) and pulse wave velocity (PWV). AP is the difference between the first and second systolic peaks on the central pressure waveform [15]. AIx was calculated by AP as a percentage of the entire pressure waveform height. PWV is the path length divided by transit time.

\subsection{Body Mass Analysis}

Non-invasive body mass analysis was performed using the Segmental Body Composition Analyzer (Tanita Pro, Tokyo, Japan). After the gender, age and height information had been entered into the device, patients were asked to stand barefoot in a stable position. The implement provided body mass analysis for legs, arms and whole body-using an algorithm incorporating impedance, age and height, to assess total and regional fat mass (FM) and fat-free mass (FFM) [16]. We also measured the following parameters: total body water (TBW), and extracellular (ECW) and intracellular (ICW) water. Additionally, extracellular water ratio normalized for total body water $(\mathrm{ECW} / \mathrm{TBW} \times 100 \%)$ was calculated [17]. $\mathrm{ECW} / \mathrm{TBW} \times 100 \%$ is a significant indicator of body water balance.

\subsection{Statistical Analysis}

The STATISTICA 13.1 software package (StatSoft, Kraków, Poland) was used for analysis. The Shapiro-Wilk test assessed the normality of distribution. The two-tailed Student's $t$-test for normal distributed data and Mann-Whitney U test for non-normally distributed variables were used. The receiver-operating characteristic curve (ROC) for significant continuous data in univariate analyses was prepared and the Youden index was used to transform these data from continuous into categorical ones. These categorical data were tested by backward stepwise multivariate logistic regression. All results were considered significant at $p<0.05$.

\section{Results}

\subsection{Evaluation of Basic Characteristics}

Demographics, clinical characteristics, biochemical parameters and biomarkers according to VO2 quartiles (the lowest characteristic compared with better oxygen consumption) are presented in Table 1. Average age was lower in the group with the lowest oxygen consumption $(51( \pm 8)$ vs. $55( \pm 8), p=0.005)$. Body mass and body mass index (BMI) were significantly higher in women with the lowest exercise capacity (median 81.45 vs. $68.8 \mathrm{~kg}, p<0.0001$ and median 30.34 vs. $25.85 \mathrm{~kg} / \mathrm{m}^{2}, p<0.0001$, respectively). Women 
with the lowest oxygen consumption had a significantly higher level of hs-cTnT (median 4.5 vs. $3.4 \mathrm{pg} / \mathrm{mL}, p=0.001$ ) although there was no difference in NT-proBNP level. The differences in other characteristics were not statistically significant. Data are presented in Table 1.

Table 1. Evaluation of basic characteristics.

\begin{tabular}{|c|c|c|c|}
\hline Parameter & $\begin{array}{l}\text { Group in the Lowest Percentile of } \\
\qquad \mathrm{VO}_{2 \max }(<17 \mathrm{~mL} / \mathrm{kg} / \mathrm{min}) \\
n=54\end{array}$ & $\begin{array}{c}\text { Group in Higher Percentiles } \\
\text { of } \mathrm{VO}_{2 \max } \\
n=131\end{array}$ & $p$ \\
\hline Age & $51.28( \pm 8.13)$ & $54.94( \pm 7.54)$ & 0.005 \\
\hline Height $(\mathrm{cm})$ & $(160-167), 164$ * & $(160-167), 163$ * & 0.28 \\
\hline Body mass (kg) & $(71.8-93.5), 81.45$ * & $(62.1-80.2), 68.8 *$ & $<0.0001$ \\
\hline $\mathrm{BMI}\left(\mathrm{kg} / \mathrm{m}^{2}\right)$ & $(26.80-34.76), 30.34 *$ & $(22.93-29.71), 25.85 *$ & $<0.0001$ \\
\hline Glucose (mg/dL) & (87-99), 93 * & $(87-97), 92 *$ & 0.54 \\
\hline HDL cholesterol (mg/dL) & $(36-56), 47^{*}$ & $(42-61.5), 51 *$ & $<0.05$ \\
\hline LDL cholesterol (mg/dL) & $113.51( \pm 31.23)$ & $118.58( \pm 36.05)$ & 0.42 \\
\hline Triglycerides (mg/dL) & $(80-183), 124 *$ & $(82-153), 114 *$ & 0.42 \\
\hline Hemoglobin (g/dL) & $(12.5-13.9), 13.45^{*}$ & $(12.5-14.2), 13.5^{*}$ & 0.64 \\
\hline GFR $\left(\mathrm{mL} / \mathrm{min} / 1.73 \mathrm{~m}^{3}\right)$ & $(75.8-96.1), 85.25 *$ & $(76.5-100.3), 86.1^{*}$ & 0.6 \\
\hline ALT (U/L) & $(14-27), 20$ * & $(14-27), 19$ * & 0.98 \\
\hline AST (U/L) & $(20-26), 23$ * & $(19-26), 22$ * & 0.46 \\
\hline hs-CRP (mg/L) & $(0.5-0.76), 0.5^{*}$ & $(0.5-0.56), 0.5^{*}$ & 0.1 \\
\hline hs-cTnT (pg/mL) & $(3.4-5.9), 4.5^{*}$ & $(3-4.7), 3.4^{*}$ & 0.001 \\
\hline NT-proBNP (pg/mL) & $(37-140), 71$ * & $(40-97), 64 *$ & 0.32 \\
\hline
\end{tabular}

*-median; Values with non-normal distribution are expressed as median (range) values. Values with normal; distributions are expressed as mean \pm standard deviation (SD). BMI—body mass index; ALT—alanine aminotransferase; AST—aspartate aminotransferase; hsCRP—high-sensitivity c-reactive protein; GFR—glomerular filtration rate; HDL—high-density lipoprotein; LDL—low-density lipoprotein; hs-cTnT-high-sensitivity cardiac troponin; NT-proBNP-N-terminal prohormone of brain natriuretic peptide.

\subsection{Evaluation of Echocardiographic and Hemodynamic Parameters}

LA volume, $\mathrm{A}^{\prime}$ and $\mathrm{E} / \mathrm{E}^{\prime}$ were significantly higher (median 62.5 vs. $52 \mathrm{~mL}, p=0.0003$; median 11 vs. $10 \mathrm{~cm} / \mathrm{s}, p=0.02$; median $8.2 \mathrm{vs} .7 .68 \mathrm{~cm} / \mathrm{s}, p=0.04$; respectively) and $\mathrm{E}^{\prime}$ was lower (median 8.5 vs. $10 \mathrm{~cm} / \mathrm{s}, p=0.001$ ) in women with $\mathrm{VO}_{2 \max }<17 \mathrm{~mL} / \mathrm{kg} / \mathrm{min}$ compared to controls. There were no statistically significant differences regarding LVEF, LAVi, TAPSE, ( $p=0.7 ; p=0.07 ; p=0.96$; respectively). The hemodynamic parameters assessed non-invasively using the SphygmoCor system had no effect on oxygen consumption in the middle-age female population. Results are presented in Table 2.

\subsection{Evaluation of Cardiocirculatory, Pulmonary and Metabolic Response to Exercise in CPET}

Patients with the lowest oxygen consumption had lower FEV1 and FVC (median 2.63 vs. $2.711, p=0.01$; median 3.15 vs. $3.34, p=0.001$; respectively) and a higher Tiffeneau index (FEV1/FVC\%) (median 108 vs. 105\%, $p=0.02$ ) compared to patients with better exercise tolerance. Exercise time was significantly longer (9.05 ( \pm 2.07$)$ vs. $7.28( \pm 1.93)$ min, $p<0.0001)$ and HRmax was higher $(150.06( \pm 16.05)$ vs. $127.17( \pm 19.89), p<0.0001)$ in patients in the lowest percentile of $\mathrm{VO}_{2 \max }$. Metabolic gas exchange measurements showed lower values of $\mathrm{VO}_{2} \mathrm{AT}$, peak $\mathrm{VO}_{2}$, highest $\mathrm{VO}_{2 \mathrm{max}}, \mathrm{VE} / \mathrm{VCO}_{2}$ slope (median $10 \mathrm{vs}$. $13 \mathrm{~mL} / \mathrm{min} / \mathrm{kg}, p<0.0001$; median 1.24 vs. $1.45 \mathrm{l}, p<0.0001$; median 15 vs. $21 \mathrm{~mL} / \mathrm{min} / \mathrm{kg}$, $p<0.0001 ; 27.98( \pm 3.71)$ vs. $29.35( \pm 4.55), p=0.04$; respectively) and slightly lower RER (median 1.07 vs. $1.14, p<0.0001$ ) (Table 3 ). 
Table 2. Evaluation of selected echocardiographic and hemodynamic parameters among the groups.

\begin{tabular}{|c|c|c|c|}
\hline Parameter & $\begin{array}{l}\text { Group in the Lowest Percentile of } \\
\mathrm{VO}_{2 \max }(<17 \mathrm{~mL} / \mathrm{kg} / \mathrm{min}) n=54\end{array}$ & $\begin{array}{l}\text { Group in Higher Percentiles } \\
\text { of } \mathrm{VO}_{2 \max } n=131\end{array}$ & $p$ \\
\hline $\mathrm{EF}(\%)$ & $(61-65), 64 *$ & $(61-67), 64 *$ & 0.7 \\
\hline LA volume (mL) & $(55-71.5), 62.5^{*}$ & $(45.5-65.5), 52 *$ & 0.0003 \\
\hline $\mathrm{LAVi}\left(\mathrm{mL} / \mathrm{m}^{2}\right)$ & $(28.35-38.9), 34.03 *$ & $(27.24-35.84), 30.12 *$ & 0.07 \\
\hline $\mathrm{E}^{\prime}(\mathrm{cm} / \mathrm{s})$ & $(8-10.5), 8.5$ * & $(8.5-12), 10 *$ & 0.001 \\
\hline $\mathrm{A}^{\prime}(\mathrm{cm} / \mathrm{s})$ & $(10-12.5), 11$ * & $(9-12), 10$ * & 0.02 \\
\hline $\mathrm{E} / \mathrm{E}^{\prime}(\mathrm{cm} / \mathrm{s})$ & $(7.2-10), 8.2 *$ & $(6.56-8.7), 7.68 *$ & 0.04 \\
\hline TAPSE (mm) & $(22-26), 23$ * & $(21-27), 23$ * & 0.96 \\
\hline $\mathrm{PWV}(\mathrm{m} / \mathrm{s})$ & $(6.9-8.8), 7.65^{*}$ & $(6.8-8.5), 7.4^{*}$ & 0.36 \\
\hline Aortic SP (mmHg) & $(112-130), 119 *$ & $(109-129), 118$ * & 0.36 \\
\hline Aortic PP (mmHg) & $(41-80), 68.5$ * & $(41-80), 63$ * & 0.64 \\
\hline $\mathrm{AP}(\mathrm{mmHg})$ & $(9-17), 13$ * & $(10-15), 12 *$ & 0.5 \\
\hline Alx (\%) & $(23-42), 31.5$ * & $(27-37), 32 *$ & 0.91 \\
\hline Alx@HR75 (\%) & $(22-36), 27.5$ * & $(23-35), 32 *$ & 0.74 \\
\hline
\end{tabular}

*-median; Values with non-normal distribution are expressed as median (range) values. Values with normal distributions are expressed as mean \pm standard deviation (SD). aortic $\mathrm{SP}$-aortic systolic pressure; aortic $\mathrm{PP}$-aortic pulse pressure; $\mathrm{AP}$-augmentation pressure; AIx-augmentation index; AIx@HR75—adjusted augmentation index at heart rate 75/min; A' - late diastolic mitral annulus velocity; $\mathrm{E} / \mathrm{E}^{\prime}$-ratio of peak velocity of early diastolic transmitral flow to peak velocity of early diastolic mitral annular motion as determined by pulsed wave Doppler; $\mathrm{E}^{\prime}$ — early diastolic mitral annular velocity; LA—left atrium; LAVi—left atrial volume index; LV—left ventricle; EF-left ventricular ejection fraction; PWV—pulse wave velocity; TAPSE—-tricuspid annular plane systolic excursion.

Table 3. Evaluation of spiroergometric parameters.

\begin{tabular}{|c|c|c|c|}
\hline Parameter & $\begin{array}{l}\text { Group in the Lowest Percentile of } \\
\mathrm{VO}_{2 \max }(<17 \mathrm{~mL} / \mathrm{kg} / \mathrm{min}) n=54\end{array}$ & $\begin{array}{l}\text { Group in Higher Percentiles } \\
\text { of } \mathrm{VO}_{2 \max } n=131\end{array}$ & $p$ \\
\hline Exercise time (min) & $9.05( \pm 2.07)$ & $7.28( \pm 1.93)$ & $<0.0001$ \\
\hline HR max & $150.06( \pm 16.05)$ & $127.17( \pm 19.89)$ & $<0.0001$ \\
\hline Peripheral SBP max (mmHg) & $(160-190), 180$ * & $(160-190), 170$ * & 0.88 \\
\hline Peripheral DBP max (mmHg) & $(80-90), 80$ * & $(80-90), 80$ * & 0.44 \\
\hline FEV1 (L) & $(2.19-2.87), 2.63$ * & $(2.48-2.98), 2.71 *$ & 0.01 \\
\hline FVC (L) & $(2.48-3.34), 3.15$ * & $(2.97-3.75), 3.34$ * & 0.001 \\
\hline $\mathrm{FVC} \%$ & $(95-115), 105 *$ & $(101.5-123.5), 111$ * & 0.001 \\
\hline FEV1/FVC & $(79-88), 85$ * & $(78-87), 83 *$ & 0.13 \\
\hline $\mathrm{FEV} 1 / \mathrm{FVC} \%$ & $(100-113), 108^{*}$ & $(98-109), 105 *$ & 0.02 \\
\hline FEF 25-75 & $(1.65-3.13), 2.43$ * & $(1.88-3.19), 2.59 *$ & 0.13 \\
\hline RER & $(1.01-1.12), 1.07$ * & $(1.09-1.18), 1.14$ * & $<0.0001$ \\
\hline $\mathrm{VO}_{2 \max }(\mathrm{mL} / \mathrm{min} / \mathrm{kg})$ & $(14-16), 15^{*}$ & $(18-23), 21$ * & $<0.0001$ \\
\hline $\mathrm{VO}_{2} \mathrm{AT}(\mathrm{mL} / \mathrm{min} / \mathrm{kg})$ & $(9-11), 10$ * & $(12-15), 13$ * & $<0.0001$ \\
\hline Peak $\mathrm{VO}_{2 \max }(\mathrm{L} / \mathrm{min})$ & $(1.09-1.4), 1.24$ * & $(1.29-1.64), 1.45^{*}$ & $<0.0001$ \\
\hline $\mathrm{VE} / \mathrm{VCO}_{2}$ slope & $27.98( \pm 3.71)$ & $29.35( \pm 4.55)$ & 0.04 \\
\hline
\end{tabular}

*-median; Values with non-normal distribution are expressed as median (range) values. Values with normal distributions are expressed as mean \pm standard deviation (SD). DBP—diastolic blood pressure; SBP—systolic blood pressure; FEV1—forced expiratory volume in one second; FVC—forced vital capacity; FEV1/FVC — ratio of forced expiratory volume in one second to forced vital capacity; FEF 25-75\% - forced expiratory flow over the middle one half of the FVC; RER-respiratory exchange ratio; $\mathrm{VO}_{2 \max }$-the maximum amount of oxygen the body can utilize during a specified period of usually intense exercise; $\mathrm{VO}_{2} \mathrm{AT}$-oxygen uptake at anaerobic threshold per kilogram; peak $\mathrm{VO}_{2}$ - highest respiratory oxygen uptake $\left(\mathrm{VO}_{2}\right)$ achieved by the subject during the maximal exercise; $\mathrm{VE} / \mathrm{VCO} 2$ slope- the minute ventilation/carbon dioxide production slope. 


\subsection{Evaluation of Body Mass Analysis}

Female patients with the lowest exercise tolerance in CPET had significantly higher BIA parameters: levels of fat as a percentage and in kilograms (median $38.3 \mathrm{vs.} 33.75 \%$, $p<0.0001$; median 30.4 vs. $23.8 \mathrm{~kg}, p<0.0001$; respectively), FFM (median 53.8 vs. $44.8 \mathrm{~kg}$, $p<0.0001$ ); TBW (median 36.25 vs. $32.4 \mathrm{~kg}, p=0.0002$ ); ECW (median 16.7 vs. 14.4, $p<0.0001$ ); ICW (median 19.3 vs. $18, p=0.005$ ); ECW $/$ TBW $\times 100 \%$ (median 46.5 vs. $45, p<0.0001$ ); metabolic age (median 61 vs. 47, $p<0.0001$ ) compared to counterparts. TBW percentage was lower (median 43.7 vs. $47.1, p<0.0001$ ) in patients with $\mathrm{VO}_{2 \max }<17 \mathrm{~mL} / \mathrm{kg} / \mathrm{min}$ than in controls. Results are presented in Table 4 .

Table 4. Evaluation of body composition parameters.

\begin{tabular}{|c|c|c|c|}
\hline Parameter & $\begin{array}{l}\text { Group in the Lowest Percentile of } \\
\mathrm{VO}_{2 \max }(<17 \mathrm{~mL} / \mathrm{kg} / \mathrm{min}) n=54\end{array}$ & $\begin{array}{l}\text { Group in Higher Percentiles of } \\
\qquad \mathrm{VO}_{2 \max } n=131\end{array}$ & $p$ \\
\hline Fat $(\%)$ & $(35.8-40.8), 38.3$ * & $(29.45-38.1), 33.75$ * & $<0.0001$ \\
\hline Fat (kg) & $(27.3-37.7), 30.4$ * & (17.75-29.5), $23.8^{*}$ & $<0.0001$ \\
\hline FFM (kg) & $(50.8-56.8), 53.8 *$ & $(42.1-47.2), 44.8^{*}$ & $<0.0001$ \\
\hline TBW (kg) & $(32.1-39.5), 36.25$ * & $(30.5-35.7), 32.4$ * & 0.0002 \\
\hline TBW (\%) & $(42-45.3), 43.7^{*}$ & $(43.9-50.3), 47.1$ * & $<0.0001$ \\
\hline ECW (kg) & $(14.8-18.3), 16.7^{*}$ & $(13.6-16.2), 14.4^{*}$ & $<0.0001$ \\
\hline ICW (kg) & $(17.5-21), 19.3$ * & $(16.5-19.5), 18$ * & 0.005 \\
\hline $\mathrm{ECW} / \mathrm{TBW} \times 100 \%$ & $(45.45-47.28), 46.5^{*}$ & $(43.75-46.28), 45$ * & $<0.0001$ \\
\hline Metabolic age & $(54-67), 61$ * & $(40-59), 47$ * & $<0.0001$ \\
\hline
\end{tabular}

*-median; Values with non-normal distribution are expressed as median (range) values. Values with normal distributions are expressed as mean \pm standard deviation (SD). ECW-extracellular water; FFM-fat-free body mass; ICW-intracellular water, ECW/TBW\%-ratio of extracellular water to total body water; TBW-total body water.

\subsection{Multivariate Analysis}

Parameters with a $p$ value $<0.05$ in the univariate analysis were entered into the multivariate analysis using the logistic regression analysis. In a multiple logistic regression model, three factors were found to be significantly associated with $\mathrm{VO}_{2 \max }$ : ECW $/ \mathrm{TBW} \times$ $100 \%$ (Figure 1) (OR 4.45, 95\% CI: 1.77-11.21; $p=0.002$ ), BMI (Figure 2) (OR 7.11, 95\% CI: 2.01-25.11; $p=0.002$ ) and hs-cTnT level (OR 2.69, 95\% CI: 1.23-5.91; $p=0.013)$. Results are presented in Table 5 . The value of ECW $/$ TBW $\times 100 \%$ higher than 45 , BMI $>24.65$ and hs-cTnT level higher than $3.3 \mathrm{pg} / \mathrm{mL}$ were associated with $\mathrm{VO}_{2 \max }<17 \mathrm{~mL} / \mathrm{kg} / \mathrm{min}$.

Table 5. Multivariate analysis—stepwise logistic regression.

\begin{tabular}{ccccc}
\hline \multirow{2}{*}{ Variable } & \multirow{2}{*}{ OR } & \multicolumn{2}{c}{ 95\% CI for OR } & \multirow{2}{*}{$p$} \\
\cline { 3 - 4 } & & Lower Limit & Upper Limit & \\
\hline ECW $/$ TBW $\times 100 \%$ & 4.45 & 1.77 & 11.21 & 0.002 \\
\hline BMI & 7.11 & 2.01 & 25.11 & 0.002 \\
\hline hs-cTnT & 2.69 & 1.23 & 5.91 & 0.013 \\
\hline
\end{tabular}

ECW/TBW—extracellular water to total body water ratio; BMI—body mass index; hs-cTnT—high-sensitivity cardiac troponin T; OR—odds ratio; CI—confidence interval. 


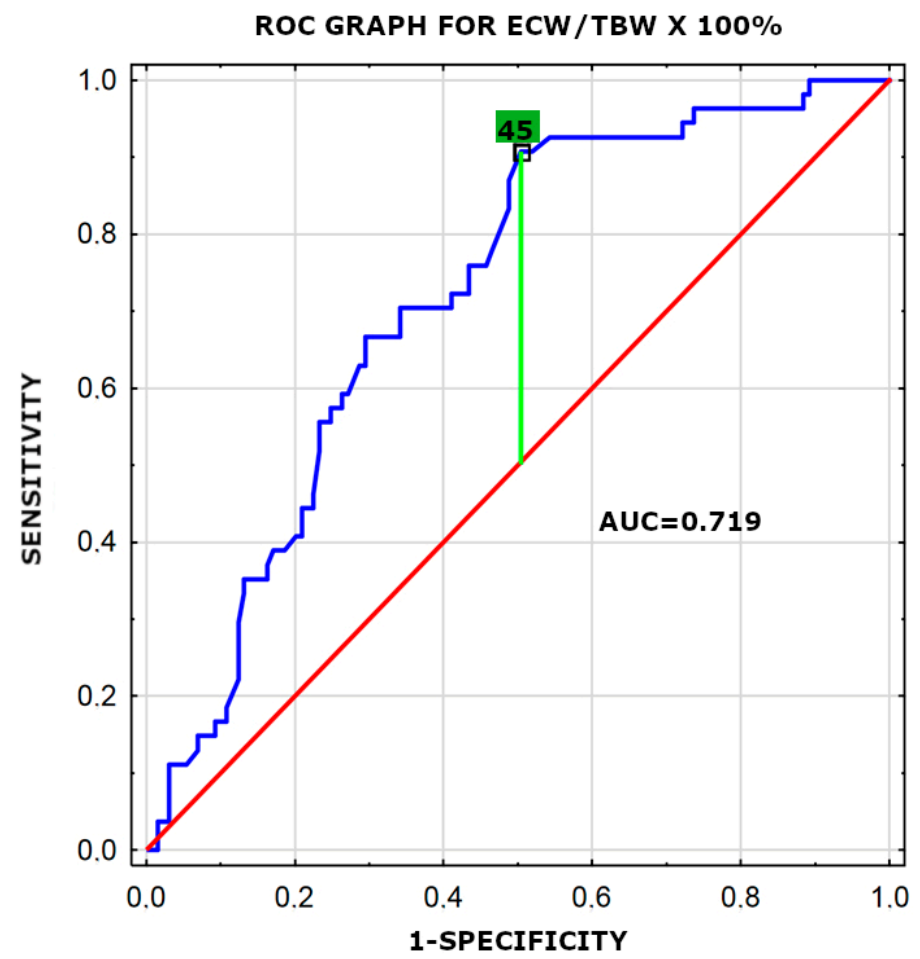

Figure 1. Receiver-operating characteristic curve $(\mathrm{ROC})$ for the $\mathrm{ECW} / \mathrm{TBW} \times 100 \%$ variable revealing its diagnostic potential. AUC -area under the ROC curve.

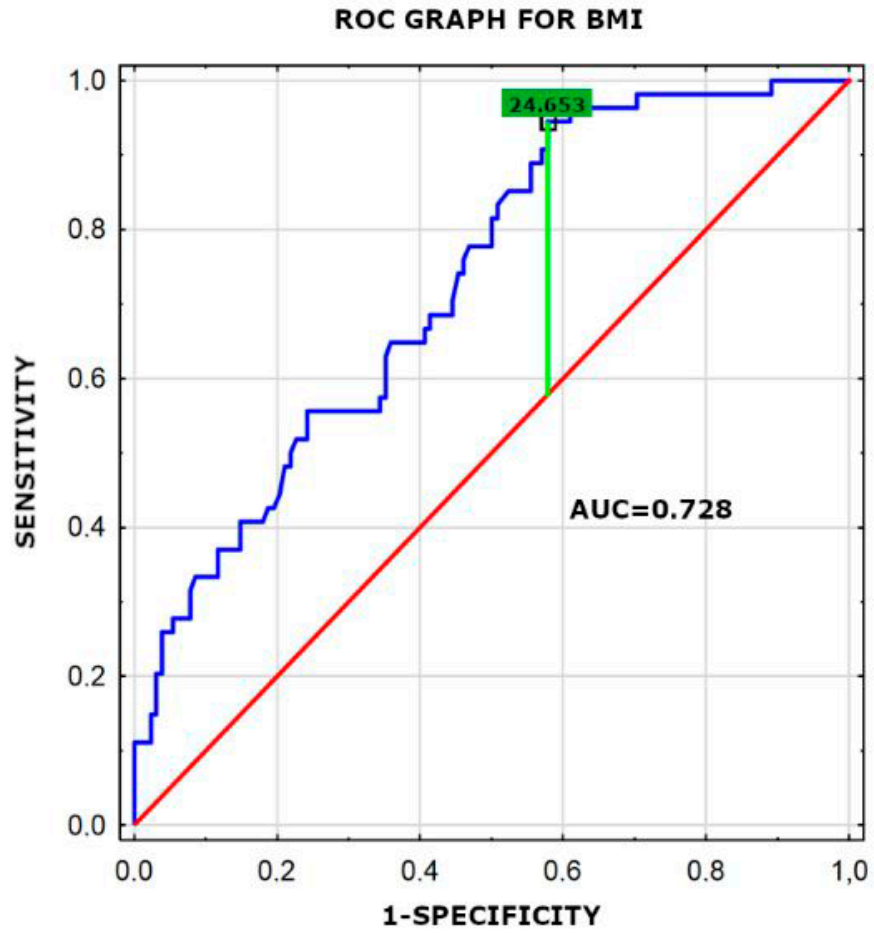

Figure 2. Receiver-operating characteristic curve (ROC) for the BMI variable revealing its diagnostic potential. AUC -area under the ROC curve.

\section{Discussion}

The current study shows that selected parameters of diastolic left ventricular dysfunction and increased high-sensitivity troponin but not NT-proBNP levels and parameters 
of arterial stiffness, or central and peripheral blood pressures are connected with the lowest oxygen uptake assessed in CPET in hypertensive women. Pulmonary function measured in spirometry was worse and the assessment of the exercise response parameters in CPET were lower in patients with $\mathrm{VO}_{2 \max }<17 \mathrm{~mL} / \mathrm{kg} / \mathrm{min}$ than in the group with better exercise capacity. Women in the lowest percentile of $\mathrm{VO}_{2 \max }$ also had significantly higher BMI, fat content ( $\mathrm{kg}$ and \%), higher FFM (kg), higher TBW as well as ECW and ICW, ECW $/ \mathrm{TBW} \times 100 \%$ and metabolic age compared to counterparts. TBW percentage, however, was lower in patients with $\mathrm{VO}_{2 \max }<17 \mathrm{~mL} / \mathrm{kg} / \mathrm{min}$ than in controls. In a multiple logistic regression model, the following factors were independently associated with $\mathrm{VO}_{2 \max }$ : ECW $/ \mathrm{TBW} \times 100 \%$ (higher than 45), BMI (>24.65) and hs-cTnT level $(>3.3 \mathrm{pg} / \mathrm{mL})$.

Exercise capacity has become a well-established independent predictor for cardiovascular disease [18]. $\mathrm{VO}_{2}$, expressed as $\mathrm{VO}_{2}$ per kilogram, is used to investigate the performance of the respiratory-cardiovascular system. This parameter offers the best risk stratification across the heart failure cohort including women and the obese [19]. Hulens et al. assessed the differences in submaximal and maximal exercise capacity parameters between 81 lean and 225 obese women. At a submaximal intensity load of $70 \mathrm{~W}$, oxygen uptake $\left(\mathrm{VO}_{2}\right)$ was larger in the obese women and was already $78 \%$ of their peak $\mathrm{VO}_{2}$, whereas in the non-obese it was only $69 \%(p=0.0001)$. Slim females recovered better. After 2 min they were already at $35 \%$ of the peak $\mathrm{VO}_{2}$, while in the obese females it was $47 \%(p=0.0001)$. These results confirm that exercise capacity is decreased in obesity and are in accordance with our results, where women with the lowest exercise capacity had higher BMI and fat mass [20]. Babb et al. also supported our results in the study which investigated the effect of moderate obesity on ventilatory responses to graded exercise and compared the ventilatory responses of ten moderately obese ( $35+/-5 \%$ body fat) and nine slim women $(22+/-2 \%$ body fat) during an incremental treadmill walking test. At $10.0 \%$ and $12.5 \%$ grade, respiratory oxygen uptake $\left(\mathrm{VO}_{2}\right)$ was lower and ventilatory equivalents for oxygen were larger in the obese women. The difference in $\mathrm{VE} / \mathrm{VO}_{2}$ suggested a lower ventilatory threshold for the obese women [21].

Cardiac troponin $\mathrm{T}(\mathrm{cTnT})$ and troponin $\mathrm{I}(\mathrm{cTnI})$ are cardiac proteins that control the interaction between actin and myosin [22]. The troponin complex is located on the myofibrillar thin (actin) filament of striated (skeletal and cardiac) muscle. The levels of cTnI and TnT were evaluated using monoclonal antibodies in immunometric assay formats resulting in clinical assays specific to myocardial injury [23]. In the study of Ebong et al. the authors investigated the effects of early menopause (occurrence before 45 years of age) and hs-cTnT elevation ( $\geq 14 \mathrm{ng} / \mathrm{L}$ ) on heart failure (HF) incidence in 2276 postmenopausal women aged 67-90 years. The hs-cTnT elevation was related to higher HF incidence with or without early menopause (3.03 (95\% CI, 1.59-5.77)) and (3.29 (95\% CI, 2.08-5.21)), respectively, but this relationship was partly explained by HF risk factors [24].

Extracellular fluid status was defined as extracellular water to total body water ratio (ECW/TBW) measured using bioelectrical impedance analysis. The measurement of $\mathrm{ECW} / \mathrm{TBW}$ ratio is a simple and fast indicator of hydration status. The ECW/TBW ratio is used as a marker of the extracellular volume status. The study of Waki et al. indicated that fluid volumes are increased in obese women, and the expansion is relatively greater for the extracellular compartment [25]. In another study of 95 participants with end-stage chronic kidney disease on dialysis therapy, ECW / TBW ratio presented the strongest correlation with decreased exercise tolerance $(\mathrm{R}=-0.63 ; p<0.001)$ [26].

In our study, a value of ECW $/ \mathrm{TBW} \times 100 \%$ higher than 45 and BMI $>24.65$ were independently associated with the lowest exercise tolerance in hypertensive women. There is a paucity of research assessing the relationship between fluid distribution, body mass and exercise tolerance in hypertensive women aged over 40 in stage A heart failure. Our findings provide new evidence in this field and indicate that therapeutic strategies targeting fluid status and body mass compartments may increase the exercise capacity of middle-age females with hypertension. 
There are several limitations of the present study, which included a small study population (185 women in the perimenopausal period) without healthy controls. The patient population was limited to those hospitalized due to HA in our department, which could have caused referral bias because patients referred for hospitalization were not representative of the general HA population. Because the disease severity in our patients was mild or moderate, the results should be carefully interpreted when applied to different populations. In addition, the study design was limited regarding the evaluation of the effect of medications. Moreover, an echocardiogram was performed only at rest. Finally, the present study only included stable patients who were able to undergo CPET. Hence, the present results need to be interpreted with caution and should be reproduced in a larger HA population, preferably in a prospective controlled clinical trial.

Despite these limitations, this is to our best knowledge the first study of hypertensive women in the perimenopausal period to evaluate the risk of heart failure, assessing the impact of high-sensitivity cardiac troponin level on the development of heart failure in hypertensive female patients in perimenopausal age. We demonstrated that overhydration also played an important role in HA patients and the risk of heart failure. Hydration status should be considered in overall patient care.

\section{Conclusions}

High-sensitivity cardiac troponin may serve as an early biomarker of heart failure in hypertensive women. Hydration status should be considered in the overall hypertensive care of women. Body mass compartments analysis in early identification of hypertensive females at risk of heart failure. Optimization and personalization of body structure may be a preventive method for this disease.

Author Contributions: Conceptualization, A.B.-D. and K.G.; methodology, A.B.-D., K.J., M.M.; software, A.S.; validation, A.B.-D., K.G. and S.v.H.; formal analysis, A.S.; investigation, K.J., K.G.; resources, K.G.; data curation, A.B.-D., K.J., K.G.; writing—original draft preparation, K.G.; writingreview and editing, A.B.-D.; visualization, M.B. and M.M.; supervision, M.B. and S.v.H.; project administration, A.B.-D.; funding acquisition, A.B.-D. All authors have read and agreed to the published version of the manuscript.

Funding: This research received no external funding.

Institutional Review Board Statement: The study was conducted according to the guidelines of the Declaration of Helsinki, and approved by the Ethics Committee of Polish Mother's Memorial Hospital Research Institute (PMMHRI-BCO.71/2020).

Informed Consent Statement: Informed consent was obtained from all subjects involved in the study. Written informed consent has been obtained from the patient(s) to publish this paper.

Data Availability Statement: Individual participant data that underlie the results reported in this article after deidentification (text, tables, figures and appendices) as well as study protocol will be available for researchers who provide a methodologically sound proposal. Proposals may be submitted after 9 months and up to 36 months following article publication.

Conflicts of Interest: The authors declare no conflict of interest.

\section{References}

1. NCD Risk Factor Collaboration (NCD-RisC). Worldwide trends in blood pressure from 1975 to 2015: A pooled analysis of 1479 population-based measurement studies with $19 \cdot 1$ million participants. Lancet 2017, 389, 37-55. [CrossRef]

2. Bielecka-Dabrowa, A.; Aronow, W.S.; Rysz, J.; Banach, M. The rise and fall of hypertension: Lessons learned from Eastern Europe. Curr. Cardiovasc. Risk Rep. 2011, 5, 174-179. [CrossRef] [PubMed]

3. Savarese, G.; Lund, L.H. Global Public Health Burden of Heart Failure. Card. Fail. Rev. 2017, 3, 7-11. [CrossRef]

4. Okoth, K.; Chandan, J.S.; Marshall, T.; Thangaratinam, S.; Thomas, G.N.; Nirantharakumar, K.; Adderley, N.J. Association between the reproductive health of young women and cardiovascular disease in later life: Umbrella review. BMJ 2020, 7, m3502. [CrossRef]

5. Savarese, G.; D'Amario, D. Sex differences in heart failure. Adv. Exp. Med. Biol. 2018, 1065, 529-544. [CrossRef] [PubMed] 
6. Davis, S.R.; Lambrinoudaki, I.; Lumsden, M.; Mishra, G.D.; Pal, L.; Rees, M.; Santoro, N.; Simoncini, T. Menopause. Nat. Rev. Dis. Primers 2015, 1, 15004. [CrossRef]

7. Messerli, F.H.; Rimoldi, S.F.; Bangalore, S. The transition from hypertension to heart failure: Contemporary update. JACC Heart Fail. 2017, 5, 543-551. [CrossRef]

8. Herdy, A.H.; Ritt, L.E.; Stein, R.; Araújo, C.G.; Milani, M.; Meneghelo, R.S.; Ferraz, A.S.; Hossri, C.; Almeida, A.E.; Fernandes-Silva, M.M.; et al. Cardiopulmonary exercise test: Background, applicability and interpretation. Arq. Bras. Cardiol. 2016, 107, 467-481. [CrossRef]

9. Saric, M.; Armour, A.C.; Arnaout, M.S.; Thomas, G.N.; Nirantharakumar, K. Guidelines for the use of echocardiography in the evaluation of a cardiac source of embolism. J. Am. Soc. Echocardiogr. 2016, 29, 1-42. [CrossRef]

10. D’Andrea, A.; Riegler, L.; Rucco, M.A.; Cocchia, R.; Scarafile, R.; Salerno, G.; Martone, F.; Vriz, O.; Caso, P.; Calabrò, R.; et al. Left atrial volume index in healthy subjects: Clinical and echocardiographic correlates. Echocardiography 2013, 30, 1001-1007. [CrossRef]

11. Daskalov, I.R.; Petrovsky, P.D.; Demirevska, L.D. Mitral annular systolic velocity as a marker of preclinical systolic dysfunction among patients with arterial hypertension. Cardiovasc. Ultrasound. 2012, 28, 46. [CrossRef] [PubMed]

12. Datta, D.; Normandin, E.; ZuWallack, R. Cardiopulmonary exercise testing in the assessment of exertional dyspnea. Ann. Thorac. Med. 2015, 10, 77-86. [CrossRef] [PubMed]

13. Bjørke, A.C.H.; Raastad, T.; Berntsen, S. Criteria for the determination of maximal oxygen uptake in patients newly diagnosed with cancer: Baseline data from the randomized controlled trial of physical training and cancer (Phys-Can). PLoS ONE 2020, 11, e0234507. [CrossRef]

14. Martin, J.S.; Borges, A.R.; Christy, J.B. Considerations for SphygmoCor radial artery pulse wave analysis: Side selection and peripheral arterial blood pressure calibration. Hypertens. Res. 2015, 38, 675-683. [CrossRef] [PubMed]

15. Milan, A.; Zocaro, G.; Leone, D.; Tosello, F.; Buraioli, I.; Schiavone, D.; Veglio, F. Current assessment of pulse wave velocity: Comprehensive review of validation studies. J. Hypertens. 2019, 37, 1547-1557. [CrossRef]

16. Jaafar, Z.A.; Kreidieh, D.; Itani, L.; Tannir, H.; El Masri, D.; El Ghoch, M. Cross-validation of prediction equations for estimating the body fat percentage in adults with obesity. Clin. Nutr. ESPEN 2021, 41, 346-350. [CrossRef] [PubMed]

17. Nishikawa, H.; Yoh, K.; Enomoto, H.; Rucco, M.A.; Cocchia, R. Extracellular water to total body water ratio in viral liver diseases: A study using bioimpedance analysis. Nutrients 2018, 10, 1072. [CrossRef]

18. Israel, A.; Kivity, S.; Sidi, Y.; Segev, S.; Berkovitch, A.; Klempfner, R.; Lavi, B.; Goldenberg, I.; Maor, E. Use of exercise capacity to improve SCORE risk prediction model in asymptomatic adults. Eur. Heart J. 2016, 1, 2300-2306. [CrossRef]

19. Ross, R.; Blair, S.N.; Arena, R.; Church, T.S.; Després, J.P.; Franklin, B.A.; Haskell, W.L.; Kaminsky, L.A.; Levine, B.D.; Lavie, C.J.; et al. Importance of assessing cardiorespiratory fitness in clinical practice: A case for fitness as a clinical vital sign: A scientific statement from the American Heart Association. Circulation 2016, 134, 653-699. [CrossRef]

20. Hulens, M.; Vansant, G.; Lysens, R.; Claessens, A.L.; Muls, E. Exercise capacity in lean versus obese women. Scand. J. Med. Sci. Sports 2001, 11, 305-309. [CrossRef]

21. Babb, T.G.; Korzick, D.; Meador, M.; Hodgson, J.L.; Buskirk, E.R. Ventilatory response of moderately obese women to submaximal exercise. Int. J. Obes. 1991, 15, 59-65. [PubMed]

22. Park, K.C.; Gaze, D.C.; Collinson, P.O.; Marber, M.S. Cardiac troponins: From myocardial infarction to chronic disease. Cardiovasc. Res. 2017, 113, 1708-1718. [CrossRef]

23. Shah, K.S.; Maisel, A.S.; Fonarow, G.C. Troponin in heart failure. Heart Fail. Clin. 2018, 14, 57-64. [CrossRef] [PubMed]

24. Ebong, I.A.; Wilson, M.D.; Bertoni, A.G.; Appiah, D.; Polonsky, T.; Michos, E.D.; Ballantyne, C.; Chang, P. High-sensitivity cardiac troponin $\mathrm{T}$ and the risk of heart failure in postmenopausal women of the ARIC Study. Menopause 2021, 4. [CrossRef]

25. Waki, M.; Kral, J.G.; Mazariegos, M.; Wang, J.; Pierson, R.N., Jr.; Heymsfield, S.B. Relative expansion of extracellular fluid in obese vs. nonobese women. Am. J. Physiol. 1991, 261, 199-203. [CrossRef] [PubMed]

26. Zuo, M.L.; Yue, W.S.; Yip, T.; Ng, F.; Lam, K.F.; Yiu, K.H.; Lui, S.L.; Tse, H.F.; Siu, C.W.; Lo, W.K. Prevalence of and associations with reduced exercise capacity in peritoneal dialysis patients. Am. J. Kidney Dis. 2013, 62, 939-946. [CrossRef] 